\title{
Zn0 Nanoparticles: Recent Biomedical Applications and Interaction with Proteins
}

\author{
Amit Kumar Bhunia* \\ Department of physics and Technophysics, Vidyasagar University University, India \& Department of Physics, Government General Degree college at \\ Gopiballavpur-II, India
}

Submission: May 08, 2017; Published: July 26, 2017

*Corresponding author: Amit Kumar Bhunia, Department of Physics \& Technophysics, Vidyasagar University, India,

Email: amitphysics87@gmail.com

\begin{abstract}
From the last decade, Nanoscience and nanotechnology have been multiple explored for vast research in medical science. Different optical and structural properties of Zinc oxide nanoparticles (ZnO NPs) are great interest in the nanoparticle based drug delivery bio-imaging, pharmaceutical applications for mankind. ZnO nanoparticles are useful for sunscreen lotion, various cosmetic products, Drug Delivery, Biomedical imaging, Gene delivery, Biosensors, MRI, and therapy. Due to the large free surface energy, nanoparticles (NPs) are highly reactive. Hence they interact with bio molecules. Before different biomedical applications of $\mathrm{ZnO}$ nanoparticles, it is useful to study their effect on biomolecules. This mini review discusses about the different biomedical applications of $\mathrm{ZnO}$ nanoparticles and the interaction of $\mathrm{ZnO}$ nanoparticles with protein molecules as reported by the different researchers.
\end{abstract}

\section{Mini Review}

Zinc Oxide ( $\mathrm{ZnO})$ is very well known multifunctional wide and direct band gap $(3.37 \mathrm{eV})$ semiconductor nanostructures. It's have excellent size dependent tunable optical property. $\mathrm{ZnO}$ has large excitonic binding energy of $60 \mathrm{meV}$ at room temperature [1]. It is an important optical nonlinear crystal due to noncentrosymmetric structure resulting from hexagonal wurtzite phase. $\mathrm{ZnO}$ nanocrystals possess large second and third order nonlinearities, resulting in the production of SHG, SFG, and electronic four wave mixing (FWM), which could be successfully applied for biological microscopy. The commonly used CdTe, CdSe nanoparticles are toxic for biological systems. Therefore, much effort has been devoted to the development of less toxic fluorescent nanoparticles such as $\mathrm{ZnO}$ nanoparticles and $\mathrm{ZnO}$ based composites.

\section{Biomedical applications}

ZnO nanoparticles are efficient for excitonic blue, near-UV emission and green luminescence related to oxygen vacancies [2]. This property of emission is important for cellular imaging. Due to the fluorescence, the penetration of $\mathrm{ZnO}$ nanoparticles in animal skin was imaged in vitro and in vivo [3]. The optical band gap and emission properties of $\mathrm{ZnO}$ nanoparticles can be tuned by doping with appropriate elements. $\mathrm{Co}, \mathrm{Cu}$, or Ni doped ZnO NPs are useful for tuning the optical properties and these materials were employed for cellular imaging studies in various cells [3]. Gd doped ZnO nanoparticles are handy for magnetic resonance and fluorescence imaging (MRI-FI) nanoprobes. ZnO NPs have been employed to fluorescence lifetime imaging in human skin. ZnO nanomaterials are versatile nanoplatforms for drug delivery applications, due to their large surface area, versatile phototoxic effect, surface chemistry, among others. In vitro studies have shown that $\mathrm{ZnO}$ nanoparticles can be highly toxic to cancer cells or leukemic T cells $[4,5]$. Hence, they have also been studied for cancer therapy. $\mathrm{Fe}_{3} \mathrm{O}_{4}-\mathrm{ZnO}$ core-shell nanoparticles are important for cancer imaging and therapy. Upon uptake of photosensitizers into cancer cells, irradiation with light of suitable wavelength and dosage can generate reactive oxygen species (ROS) which can induce cell death [6]. $\mathrm{ZnO}$ nanoparticles can induce ROS (hydroxyl radical, superoxide, hydrogen peroxide) in aqueous solutions upon absorption of UV illumination, making them good candidates for PDT [7]. ZnO nanoparticles are important for Gene Delivery. Recently Gene therapy has attracted considerable interest for cancer treatment [8]. A wide variety of nanomaterials have been investigated for gene therapy and delivery applications, including $\mathrm{ZnO}$ nanomaterials which have shown promise in various literature reports [9]. The different properties of $\mathrm{ZnO}$ nanoparticles like high catalytic efficiency, high isoelectric point (IEP; 9.5), strong 
adsorption capability, are suitable for adsorption of certain biomolecules (e.g proteins) by electrostatic interaction [10]. The high surface area, good stability, low toxicity, and high electron transfer capability also make them promising nanomaterials for biosensors [11]. The majority of reported $\mathrm{ZnO}$ nanocrystalbased biosensors are for the detection of various small molecule analytes such as glucose, phenol, $\mathrm{H}_{2} \mathrm{O}_{2}$, cholesterol, Enzyme, urea, etc [12-14]. Recently, several important reports appeared on ZnO-based glucose biosensors [15]. ZnO nanoparticles are used for Phenol Biosensors. Phenolic compounds are highly toxic to few animals and plants. Since they commonly exist in industrial waste, it is important to detect and measure them for environmental monitoring. Among the many analytical methods developed for detection of phenolic compounds, biosensors based on immobilization of tyrosinase were shown to be convenient, high sensitive, and effective [16]. Many of these biosensors have been fabricated on a platform of $\mathrm{ZnO}$ nanoparticles, because of the inherent electrostatic attraction between electropositive $\mathrm{ZnO}$ nanostructures and tyrosinase [17]. $\mathrm{ZnO}$ nanoparticles are used for $\mathrm{H}_{2} \mathrm{O}_{2}$ Biosensors. In recent report, $\mathrm{ZnO}$ nano flowers /chitosan composite matrix immobilized with enzyme HRP, were used to generate a biosensor with fine reproducibility and stability [18]. Different biosensors were constructed by immobilizing cholesterol oxidase, through either physical absorption or electrostatic interaction, onto $\mathrm{ZnO}$ nanoparticles. The first urea biosensor based on $\mathrm{ZnO}$ nanomaterials was reported in 2008, in which urease was immobilized onto $\mathrm{ZnO}$ chitosan nanobiocomposite film on ITO coated glass by physical adsorption [19]. Recently, ZnO NW arrays fabricated on gold coated plastics were also utilized in a urea biosensor, where urease was immobilized by physical adsorption [20]. Recently $1 \% \mathrm{Pt}$ or $\mathrm{Mn}$ and Co doped $\mathrm{ZnO}$ nanofilms are very good for sensing of $\mathrm{H}_{2}, \mathrm{CO}$, and ethanol vapour [21]. ZnO-based biosensors have also been reported for the detection of substances such as uric acid, lactic acid, protein, DNA [22-24]. ZnO nanoparticles are efficiently used for drug delivery nanocarriers [25,26]. Red Fluorescent Zinc Oxide Nanoparticle is novel platform for Cancer Targeting. Recent studies have shown that $\mathrm{ZnO}$ nanoparticle cores capped with polymethyl methacrylate are useful in the detection of low abundant biomarkers.

\section{Interaction of nanoparticles with protein}

The surface to volume ratio of nanoparticle is large than bulk material. This property leads to formation of large surface free energy. Due to the large free surface energy, nanoparticles (NPs) are highly reactive [27]. The knowledge about the effects of NPs on protein systems and their potential toxicity is very limited. Thus the interaction of NPs especially having luminescence property with proteins has come out as a key parameter in nanomedicine [28] and nanotoxicology [29] in the recent research. When nanoparticles are exposed to protein fluid systems, NPs form molecular complexes with encountered proteins and a dynamic layer (called 'protein-corona') of proteins is formed on the surface of NPs. The surface adsorption may lead to unfold, corona formation and protein aggregation [30]. Therefore, the concept of bio-safety and bio-compatibility of ZnO NPs is a key issue in favour of applications in biomedical applications.

\section{Review on ZnO nanoparticles-protein interaction}

The interaction of $\mathrm{ZnO}$ nanoparticles with different kind of proteins, studied by different researchers. Bardhan et al. [31-39] showed the formation of ground state complex between $\mathrm{ZnO}$ nanoparticles and BSA with static quenching of BSA. The interaction between $\mathrm{ZnO}$ nanoparticles with BSA is spontaneous and electrostatic in nature [31]. Their observation strongly indicates that the binding of $\mathrm{ZnO}$ to BSA induced some conformational change (the decreased from $64.51 \%$ in free BSA to $54.83 \%$ ) in BSA. The interaction between $\mathrm{ZnO}$ nanoparticles (average size $<40 \mathrm{~nm}$ ) with bovine haemoglobin (BHb) is studied by Mandal et al. [32]. Their spectroscopic studies on $\mathrm{BHb}$ in presence of $\mathrm{ZnO}$ nanomaterials showed the formation of a ground state complex via static quenching mechanism, with the number of binding sites, $\mathrm{n}$ being $\sim 1$. ZnO nanoparticles affect both the Soret band and the band corresponding to the tryptophan and tyrosine residues of the BHb. The CD spectra of their result showed that the content of $\alpha$-helix of BHb decreases with the addition of $\mathrm{ZnO}$ nanoparticles though the structure of $\mathrm{BHb}$ remains predominantly $\alpha$-helical even in the presence of maximum concentration of $\mathrm{ZnO}$ nanoparticles used during the experiment. The interaction between two heme proteins myoglobin ( $\mathrm{HMb}$ ) and horseradish peroxidise (HRP) with zinc oxide ( $\mathrm{ZnO})$ nanoparticles are investigated by using UV-VIS absorption, steady state fluorescence, FTIR, circular dichroism (CD) techniques by Mandal et al. [33]. They observed static mode in fluorescence quenching mechanism of $\mathrm{HMb}$ and HRP by $\mathrm{ZnO}$ nanoparticles due to formation of ground state complex. The process of binding of $\mathrm{ZnO}$ nanoparticles with the two proteins are spontaneous molecular interaction procedure. They observed that with increase in temperature there is a gradual decrease in molar ellipticity which shows the possibility of the loss of $\alpha$-helix and increase in $\beta$-sheet and random structure content in $\mathrm{HMb}-\mathrm{ZnO}$ and HRP-ZnO complex. Chakraborti et al. [34] studied the interaction of Polyethyleneimine-Functionalized ZnO Nanoparticles of core size of $\sim 3-7 \mathrm{~nm}$ with BSA [34]. They observed static and single type of protein quenching with quenching rate constant to be $4 \times 1012 \mathrm{M}-1 \mathrm{~s}-1$ by using Stern-Volmer equation. The binding between ZnO-PEI and BSA occurs via electrostatitic interactions. Their observation in UV CD spectra showed the decrease of the negative ellipticity with minor loss of helical contents of BSA after interaction with $\mathrm{ZnO}$. The secondary structure of BSA remain unchanged as the shape of the peaks and their positions remain unaltered after interaction. The effect on secondary structure of BSA is also confirmed by FTIR spectroscopy. Bhogale et al.[35] studied the interaction of $\sim 7.5 \mathrm{~nm}$ Zinc oxide ( $\mathrm{ZnO}$ ) nanoparticles with 
BSA at the three temperatures 283K, 298K, 310K [35]. Their result showed that the binding constant $(\mathrm{K})$ and number of binding sites (n) decreases with increase of temperature. The calculated thermodynamic parameters $(\Delta \mathrm{G}, \Delta \mathrm{H}$, and $\Delta \mathrm{S})$ suggest that binding occurs spontaneously involving hydrogen bond and van der Waals forces. Our research group [36-38] studies details about corona formation, emission quenching, unfolding of protein and effect of temperature on the corona of protein due to interaction with ZnO NPs. Wahab et al. [39] studied the interaction of ZnO-QDs with BSA and bovine haemoglobin (BHb) by using fluorescence quenching method and circular dichroism (CD) spectroscopy [39]. In the fluorescence spectra, quenching of fluorescence intensity of BSA with increasing concentration of $\mathrm{ZnO}-\mathrm{QDs}$ is observed. The fluorescence intensity decreases by $91 \%$ at $2 \mu \mathrm{M}$ concentration of $\mathrm{ZnO}-\mathrm{QDs}$. In addition, blue shift of $3 \mathrm{~nm}$ was observed after interacting with $2 \mu \mathrm{M} \mathrm{ZnO} \mathrm{QDs.}$

\section{References}

1. Bhunia AK, Jha PK, Rout D, Saha S (2016) Morphological Properties and Raman Spectroscopy of ZnO Nanorods. Journal of Physical Sciences 21: 111-118.

2. Heo YW, Norton DP, Pearton SJ (2005) Origin of green luminescence in $\mathrm{ZnO}$ thin film grown by molecular-beam epitaxy. J Appl Phys 98(7): 073502-073506.

3. Zvyagin AV, Zhao X, Gierden A, Sanchez W, Ross JA, et al. (2008) Imaging of zinc oxide nanoparticle penetration in human skin in vitro and in vivo. J Biomed Opt 13(6): 064031.

4. Hanley C, Layne J, Punnoose A, Reddy KM, Isaac Coombs, et al. (2008) Preferential killing of cancer cells and activated human T cells using ZnO nanoparticles. Nanotechnology 19(29): 295103.

5. Wang H, Wingett D, Engelhard MH, Feris K, Reddy KM, et al. (2009) Fluorescent dye encapsulated $\mathrm{ZnO}$ particles with cellspecific toxicity for potential use in biomedical applications. J Mater Sci Mater Med 20(1): 11-22.

6. Wilson BC, Patterson MS (2008) The physics, biophysics and technology of photodynamic therapy. Phys Med Biol 53(9): R61-R109.

7. Zhang H, Chen B, Jiang H, Wang C, Wang H, et al. (2011) A strategy for $\mathrm{ZnO}$ nanorod mediated multi-mode cancer treatment. Biomaterials 32(7): 1906-1914.

8. Patel P, Kansara K, Senapati VA, Shanker R, Dhawan A, et al. (2016) Cell cycle dependent cellular uptake of zinc oxide nanoparticles in human epidermal cells. Mutagenesis 31(4): 481-490.

9. Zhang P, Liu W (2010) ZnO QD@PMAA-co-PDMAEMA nonviral vector for plasmid DNA delivery and bioimaging. Biomaterials 31(11): 3087 3094.

10. Wang JX, Sun XW, Wei A, Y Lei, XP Cai, et al. (2006) Zinc oxide nanocomb biosensor for glucose detection. Appl Phys Lett 88: 233106.

11. Kumar SA, Chen SM (2008) Nanostructured zinc oxide particles in chemically modified electrodes for biosensor applications. Anal Lett 41(2): 141-158.

12. Dai ZH, Shao GJ, Hong JM, Bao JC, Shen J (2009) Immobilization and direct electrochemistry of glucose oxidase on a tetragonal pyramidshaped porous $\mathrm{ZnO}$ nanostructure for a glucose biosensor. Biosens Bioelectron 24(5): 1286-1291.

13. Kim JY, Jo SY, Sun GJ, Katoch A, Choi SW, et al. (2014) Tailoring the surface area of $\mathrm{ZnO}$ nanorods for improved performance in glucose sensors. Sensors and Actuators B: Chemical 192: 216-220.
14. Liu JP, Guo CX, Li CM, Yuanyuan Li, Qingbo Chi, et al. (2009) Carbon-decorated $\mathrm{ZnO}$ nanowire array: A novel platform for direct electrochemistry of enzymes and biosensing applications. Electrochem Commun 11(1): 202-205.

15. Hu FX, Chen SH, Wang C, Yuan Ruo, Yaqin Cha, et al. (2011) ZnO nanoparticle and multiwalled carbon nanotubes for glucose oxidase direct electron transfer and electrocatalytic activity investigation. J Mol Catal BEnzym 72(3-4): 298-304.

16. Wang G, Xu JJ, Ye LH, Zhu JJ, Chen HY (2002) Highly sensitive sensors based on the immobilization of tyrosinase in chitosan. Bioelectrochemistry 57(1): 33-38.

17. de Albuquerque YDT, Ferreira LF (2007) Amperometric biosensing of carbamate and organophosphate pesticides utilizing screen-printed tyrosinase-modified electrodes. Analytica Chimica Acta 596(2): 210221.

18. Liu YL, Yang YH, Yang HF, ZM Liu, RQ Yu, et al. (2005) Nanosized flowerlike $\mathrm{ZnO}$ synthesized by a simple hydrothermal method and applied as matrix for horseradish peroxidase immobilization for electrobiosensing. J Inorg Biochem 99(10): 2046-2053.

19. Solanki PR, Kaushik A, Ansari AA, Sumana G, Malhotra BD (2008) Zinc oxide-chitosan nanobiocomposite for urea sensor. Appl Phys Lett 93(16): 163903.

20. Ali SMU, Ibupoto ZH, Salman S, Magnus Willander, Bengt, et al. (2011) Selective determination of urea using urease immobilized on $\mathrm{ZnO}$ nanowires. Sensor Actuat B-Chem 160(1): 637-643.

21. Rout CS, Raju AR, Govindaraj A, Rao CN (2007) Ethanol and hydrogen sensors based on $\mathrm{ZnO}$ nanoparticles and nanowires. J Nanosci Nanotechnol 7(6): 1923-1929.

22. Usman Ali SM, Ibupoto ZH, Kashif M, Hashim U, Willander M (2012) A Potentiometric Indirect Uric Acid Sensor Based on ZnO Nanoflakes and Immobilized Uricase. Sensors (Basel) 12(3): 2787-2797.

23. Ibupoto ZH, Ali Shah SM, Khun K, Willander M (2012) Electrochemical 1-Lactic Acid Sensor Based on Immobilized ZnO Nanorods with Lactate Oxidase. Sensors (Basel) 12(3): 2456-2466.

24. Tawa K, Umetsu M, Hattori T, Kumagai I (2011) Zinc oxide-coated plasmonic chip modified with a bispecific antibody for sensitive detection of a fluorescent labeled-antigen. Anal Chem 83(15): 59445948.

25. Muhammad F, Guo M, Guo Y, Qi WL, Qu F, et al. (2011) Acid degradable $\mathrm{ZnO}$ quantum dots as a platform for targeted delivery of an anticancer drug. Mater Chem 21(35): 13406-13412.

26. Weng KC, Noble CO, Papahadjopoulos-Sternberg B, Chen FF, Drummond DC, et al. (2008) Targeted Tumor Cell Internalization and Imaging of Multifunctional Quantum Dot-Conjugated Immunoliposomes in Vitro and in Vivo. Nano Lett 8 (9): 2851-2857.

27. Nel AE, Mädler L, Velegol D, Xia T , Hoek EMV, et al. (2009) Understanding biophysicochemical interactions at the nano-bio interface. Nature materials 8: 543-557.

28. Laera S, Ceccone G, Rossi F, Gilliland D, Hussain R, et al. (2011) Measuring Protein Structure and Stability of Protein-Nanoparticle Systems with Synchrotron Radiation Circular Dichroism. Nano Lett 11(10): 4480-4484.

29.Epa VC, Burden FR, Tassa C, Weissleder R, Shaw S, et al. (2012) Modeling Biological Activities of Nanoparticles. Nano Lett 12 (11): 5808-5812.

30.Bharti B, Meissner J, Findenegg GH (2011) Aggregation of Silica Nanoparticles Directed by Adsorption of Lysozyme. Langmuir 27(16): 9823-9833. 
31. Bardhan M, Mandal G, Ganguly T (2009) Steady state, time resolved, and circular dichroism spectroscopic studies to reveal the nature of interactions of zinc oxide nanoparticles with transport protein bovine serum albumin and to monitor the possible protein conformational changes. Journal of Applied Physics 106: 034701(1-5).

32. Mandal G, Bhattacharya S, Ganguly T (2009) Investigations to reveal the nature of interactions between bovine hemoglobin and semiconductor zinc oxide nanoparticles by using various optical techniques. Chemical Physics Letters 478 (4-6): 271-276.

33. Mandal G, Bhattacharya S, Ganguly T (2011) Mode of bindings of zinc oxide nanoparticles to myoglobin and horseradish peroxidase: A spectroscopic investigations. Journal of Applied Physics 110(2): 024701.

34. Chakraborti S, Joshi P, Chakravarty D, Shanker V, Ansari ZA, et al. (2012) Interaction of Polyethyleneimine-Functionalized ZnO Nanoparticles with Bovine Serum Albumin. Langmuir 28(30): 11142-11152.
35. Bhogale A, Patel N, Sarpotdar P, Mariam J, Dongre PM, et al. (2013) Systematic investigation on the interaction of bovine serum albumin with $\mathrm{ZnO}$ nanoparticles using fluorescence spectroscopy. Colloids Surf B Biointerfaces 102: 257.

36. Bhunia AK, Samanta PK, Saha S, Kamilya T (2013) ZnO nanoparticleprotein interaction: Corona formation with associated unfolding. Appl. Phys. Lett 103: 143701.

37. Bhunia AK, Kamilya T, Saha S (2016) Temperature Dependent and Kinetic Study of the Adsorption of Bovine Serum Albumin to $\mathrm{ZnO}$ Nanoparticle Surfaces. Chemistry Select 11(1): 2872-2882.

38. Bhunia AK, Kamilya T, Saha S (2016) Synthesis, Characterization of ZnO Nanorods and its Interaction with Albumin Protein. Materials Today: Proceedings 3(2): 592-597.

39. Wahab R, Dwivedi S, Khan MS, Al-Senaidy AM, Shin HS, et al. (2014) Optical Analysis of Zinc Oxide Quantum Dots with Bovine Serum Albumin and Bovine Hemoglobin. J Pharm Innov 9(1): 48-52.

\section{Your next submission with Juniper Publishers} will reach you the below assets

- Quality Editorial service

- Swift Peer Review

- Reprints availability

- E-prints Service

- Manuscript Podcast for convenient understanding

- Global attainment for your research

- Manuscript accessibility in different formats

( Pdf, E-pub, Full Text, Audio)

- Unceasing customer service

Track the below URL for one-step submission https://juniperpublishers.com/online-submission.php 